\title{
IMPROVING NUTRITIONAL QUALITY OF THE GOAT MILK BY GRAZING
}

\author{
PAJOR, F. ${ }^{1}{ }^{*}$ - Kerti, A. ${ }^{1}$ - PENKSZA, K. ${ }^{1}$ - KUCHTIK, J. ${ }^{2}$ - HARKÁNYINÉ SZÉKElY ZS. ${ }^{1}$ - BÉRES, \\ A. ${ }^{1}-$ CZINKOTA, I. ${ }^{1}-$ SZENTES, SZ. ${ }^{1}-$ PÓTI, P. ${ }^{1}$ \\ ${ }^{I}$ Szent István University \\ H-2103, Gödöllö, Páter Károly 1. Hungary \\ ${ }^{2}$ Mendel University \\ CZ-613 00 Brno, Zemedelska 1. Czech Republic \\ *Corresponding author \\ e-mail:pajor.ferenc@mkk.szie.hu \\ (Received $12^{\text {th }}$ Sept 2013; accepted $12^{\text {th }}$ Jan 2014)
}

\begin{abstract}
The aim of study was to investigate the effect of grazing on the nutritional quality, such as composition, vitamins and fatty acids content of dairy goat milk. Before vegetation period, all goats were kept indoors and nutrition based on hay diet. After turn-out to pasture, all goats were grazing. Bulk milk samples were collected on 12 consecutive days at two sampling periods: in indoor and in grazing months and analysed for milk compositions and vitamin $\mathrm{A}, \mathrm{E}$ and $\mathrm{D}_{3}$, as well as for fatty acid contents. The milk from grazing goats had significantly higher fat, protein and total solids non-fat than goats kept indoors. Grazing caused higher concentrations of vitamin $\mathrm{A}(0.026 \mathrm{vs.} 0.036 \mathrm{mg} / 100 \mathrm{ml} ; \mathrm{P}<0.01)$ and $\mathrm{D}_{3}(0.075 \mathrm{vs}$. $0.089 \mathrm{mg} / 100 \mathrm{ml} ; \mathrm{P}<0.05)$ compared to feeding hay. During the grass diet the rumenic acid $(0.56 \mathrm{vs} .0 .66$ $\mathrm{g} / 100 \mathrm{~g}$ fatty acids; $\mathrm{P}<0.05)$ and $\mathrm{n}-3$ fatty acids $(0.36$ vs. $1.19 \mathrm{~g} / 100 \mathrm{~g}$ fatty acids; $\mathrm{P}<0.001)$ contents in milk significantly increased. In this study, n-6/n-3 ratio of 10.17 and 1.82 were found in milk samples of goats that fed indoor and grass, respectively. It can be concluded that the milk from grazing goats is more advantageous for human nutrition, than the milk produced by animals fed hay based diet.
\end{abstract}

Keywords: goat, grazing, milk, vitamins, fatty acids

\section{Introduction}

Pasture is one of the most natural feeding sources for animals. The digestibility, protein and energy content of the grass are notable, the crude fat content relatively low, $2-3 \%$ of dry matter, nevertheless the grass is rich in $\alpha$-linolenic acid (Cabiddu et al. 2005), accordingly pastures and other green forages diet have been associated with high content of n-3 fatty acids of milk fat. Feeding green forages to dairy animals increased the concentrations of long chain fatty acids, such as $\alpha$-linolenic acid and reduced linoleic acid and n-6/n-3 ratio in milk and in cheese (Tsiplakou et al., 2006; Pajor et al. 2012). It is well known, that the high ratio of $n-6 / n-3$ fatty acids is a risk factor in coronary heart disease (CHD). The recommend value for the $n-6 / n-3$ ratio is less $4: 1$ (Simopoulos, 2004).

In addition, the milk possesses other favourable components, such as rumenic acid and fat-soluble vitamins. The importance of goat milk consumption is recently increasing, because the milk compounds are beneficial effect in human diet.

Numerous studies on effect of pasture on milk fatty acids, especially on rumenic acid composition were carried out in cattle and sheep (e.g. Frelich et al. 2012 and Tsiplakou et al., 2006). The rumenic acid (c9t11CLA isomer) has a range of positive health properties such as anticarcinogenic (Ip et al., 1991) and antiatherogenic effects (Nicolosi al., 1997). In contrast, literature reports are limited about goat milk and cheese 
(El-Salam and El-Shibiny, 2012). The fat-soluble vitamins are knowingly favourable in human diet for their antioxidant potential and positive impact on health (Bergamo et al., 2003).

Moreover, there is little available information about the content of vitamins in goat milk, especially about pasture kept goats compared to other ruminants (e.g. Kondyli et al. 2007).

Thus, the aim of this study was to investigate the effect of the grazing on certain nutritional quality compounds (vitamin $\mathrm{A}, \mathrm{E}$ and $\mathrm{D}_{3}, \mathrm{n}-3$ fatty acids and rumenic acid) of goat milk.

\section{Materials and method}

\section{Experimental animals and diet}

The study was carried out in a goat farm in Borsod-Abauj-Zemplen County (Northeast Hungary). 54 Hungarian Native goats on different parities but in the same stage of lactation were involved in this study. Before grazing months (May), all goats were kept indoors and their nutrition was based on ad libitum alfalfa hay and also 350 g/day grain mix.

After turn-out to pasture the grazing group stayed all day long on the pasture; however, they were also fed with $350 \mathrm{~g}$ /day grain mix. Both groups had same composition of the grain mix, which was given twice a day in equal amounts at milking time. A commercial vitamin (A, D3, E) and trace-mineralized salt block was provided free choice to all goats. The diets were adjusted to the NRC (2007) recommendations of energy and protein requirements for dairy goats (body weight: $60 \mathrm{~kg} ; 2.5 \mathrm{~kg}$ of milk/day).

Utilization of native pasture was extensive in order to avoid over-grazing. The stocking density of the pastures grazed by the goats was about $0.5 \mathrm{AU} / \mathrm{ha}$. The main grass and legume species were Festuca pseudovina and Trifolium pratense. Other species were Elymus repens, Elymus hispidus, Bromus inermis, Calamagrostis epigeios and Arrhenatherum elatius. The average annual rainfall of the area is approx. $695 \mathrm{~mm}$. The annual green grass yield was $5.2 \mathrm{t} / \mathrm{ha}$. During the daily routine the grazing goats were driven to pasture after the morning milking, and collected in the afternoon to be milked and confined for the entire night.

Milk samples were taken at two sampling times: in mid-April and in mid-July when the goats were on average among the 30 and 120 days in lactation. Samples of pooled milk were collected twice a day during 12 consecutive days of the experimental months at 6.00 a.m. and 6.00 p.m., all milk samples were frozen and stored at $-20{ }^{0} \mathrm{C}$ until further analysis. Before laboratory analysis, twice a day gathered milk samples were combined to one sample for the analysis of chemical composition.

\section{Chemical analysis}

Fat, protein, lactose and total solids without fat contents of milk were determined using a Bentley device (Bentley Combi apparatus, Bentley Instruments Inc, Chaska, MN, USA).

The milk fat was dissolved in sodium hydroxide-methanol solution and re-esterified to methyl-esters according to the AOAC (1990) method using boron trifluoride $\left(\mathrm{BF}_{3}\right)$. Methyl esters of fatty acids were determined by gas chromatography using a Shimadzu 
GC 2010 apparatus (Japan) with a flame ionization detector (FID) and column (CP-SIL$88,100 \mathrm{~m} \times 0.25 \mathrm{~mm} \times 0.2 \mu \mathrm{m})$. The split injection ratio was 50:1. The column oven temperature was held at $80^{\circ} \mathrm{C}$ for $0 \mathrm{~min}$, then programmed at a rate of $2.5^{\circ} \mathrm{C} / \mathrm{min}$ up to $205^{\circ} \mathrm{C}$ and held for $20 \mathrm{~min}$ and then increased again to $225^{\circ} \mathrm{C}$ at $10^{\circ} \mathrm{C} / \mathrm{min}$, and held for 5 min. The injector and detector temperatures were $270^{\circ} \mathrm{C}$ and $300^{\circ} \mathrm{C}$, respectively. Helium was used as the carrier gas, applying a flow rate $28 \mathrm{~cm} / \mathrm{s}$. Peaks were identified on the basis of the retention times of standard methyl esters of individual fatty acids (Mixture Me 100, Larodan Fine Chemicals AB, Sweden). The proportions of the individual acids were calculated by the ratio of their peak area to the total area of all observed acids.

Fat-soluble antioxidants (vitamin $\mathrm{A}, \mathrm{E}$ and $\mathrm{D}_{3}$ ) were analysed using the highperformance liquid chromatographic method described by Kerti and Bardos (2006). The vitamin detection was performed at $325 \mathrm{~nm}$ for vitamin A, $290 \mathrm{~nm}$ for vitamin $\mathrm{E}$ and $265 \mathrm{~nm}$ for vitamin $\mathrm{D}_{3}$. The peak areas were integrated and quantified by using the Chrompass software (Jasco, Japan).

\section{Statistical analysis}

Effects of feeding method was analysed as independent variable. Statistical analysis was processed by the SPSS 21.0 softwer package (Shapiro-Wilk test for normality distribution, F test for equality of Variances, $t$-test and Welch's corrected t-test). Significance was taken at an alpha level of 0.05 .

\section{Results and discussion}

There was no significant difference in the milk production of the examined groups; daily milk yield during the investigation was $2.5 \mathrm{~kg}$ in control goats and $2.6 \mathrm{~kg}$ in experimental goats.

Milk composition was significantly affected by diet. Hay diet caused lower $(\mathrm{P}<0.05)$ fat $(3.11 \mathrm{~g} / 100 \mathrm{~g})$, protein $(2.94 \mathrm{~g} / 100 \mathrm{~g})$ and total solids non-fat $(7.87 \mathrm{~g} / 100 \mathrm{~g})$ composition compared to milk from pasture kept goats $(3.70,3.22$ and $8.15 \mathrm{~g} / 100 \mathrm{~g}$, no data in Table). Thus, the grazing significantly improved the milk composition during experiment. It is well known, that the goat milk fat and protein content is affected by many factors, such as breed, parity, stage of lactation and diet (Kuchtik et al., 2008; Novotna et al., 2009) and it has great effect on cheese composition. Soryal et al. (2004) in Alpine goat and Pajor et al. (2009) in Hungarian Native goat found that the grazing slightly increased the milk compositions.

The contents of the selected vitamins in the goat milk are presented in Table 1.

Table 1. Effect of grazing on vitamin content of goat milk $(\mathrm{mg} / 100 \mathrm{ml})$

\begin{tabular}{lccccc}
\hline Items & Control diet & $\begin{array}{c}\text { Experimental } \\
\text { diet }\end{array}$ & Total & SEM & P \\
\hline Vitamin A & 0.025 & 0.036 & 0.031 & 0.002 & 0.001 \\
Vitamin E & 0.122 & 0.140 & 0.131 & 0.011 & 0.454 \\
Vitamin $\mathrm{D}_{3}$ & 0.075 & 0.089 & 0.082 & 0.003 & 0.017 \\
\hline
\end{tabular}

P: level of significance 
The average contents of vitamins $\mathrm{A}$ and $\mathrm{D}_{3}$ were $0.031 \mathrm{mg}$ and $0.082 \mathrm{mg} / 100 \mathrm{ml}$. In goats reared indoor lower contents of $\mathrm{A}_{\text {and }} \mathrm{D}_{3}$ vitamins $(0.025 \mathrm{mg}$ and $0.075 \mathrm{mg} / 100$ $\mathrm{ml}$ of milk) were found compared to goats with experimental diets $(0.036 \mathrm{mg}$ and 0.089 $\mathrm{mg} / 100 \mathrm{ml}$ of milk)

Mean of vitamin E concentration was $0.131 \mathrm{mg} / 100 \mathrm{ml}$, however vitamin E contents of milk did not show any significant differences between the experimental periods. The mean values of vitamin $A$ and $E$ as well as vitamin $\mathrm{D}_{3}$ in present study were slightly higher compared to values which published by Kondyli et al. (2007) and RaynalLjutovac et al. (2008).

Our results showed that milk from grazing goats is a good dietary source of vitamins $\mathrm{A}, \mathrm{E}$ and $\mathrm{D}_{3}$ whereas these are also well known for their antioxidant potential (Bergamo et al., 2003).

The results of the fatty acid analysis of milk samples are presented in Table 2.

Table 2. Effect of grazing on fatty acid profile of goat milk ( $\mathrm{g} / 100 \mathrm{~g}$ total fatty acids)

\begin{tabular}{|c|c|c|c|c|c|}
\hline Fatty acids & Control diet & $\begin{array}{c}\text { Experimental } \\
\text { diet }\end{array}$ & Total & SEM & $\mathbf{P}$ \\
\hline $\mathrm{C} 4: 0$ & 0.58 & 0.71 & 0.64 & 0.03 & 0.037 \\
\hline C6:0 & 1.32 & 1.73 & 1.52 & 0.06 & $<0.001$ \\
\hline C8:0 & 1.68 & 2.20 & 1.94 & 0.08 & $<0.001$ \\
\hline C10:0 & 7.59 & 9.28 & 8.43 & 0.29 & 0.001 \\
\hline C12:0 & 3.40 & 3.39 & 3.40 & 0.07 & 0.971 \\
\hline C14:0 & 11.27 & 9.91 & 10.59 & 0.21 & $<0.001$ \\
\hline C14:1c9 & 0.16 & 0.08 & 0.12 & 0.01 & $<0.001$ \\
\hline C16:0 & 28.76 & 27.83 & 28.29 & 0.26 & 0.072 \\
\hline C16:1c9 & 0.96 & 0.73 & 0.84 & 0.03 & $<0.001$ \\
\hline C18:0 & 10.71 & 17.97 & 14.34 & 0.81 & $<0.001$ \\
\hline C18:1n-9c & 17.89 & 14.43 & 16.16 & 0.58 & 0.001 \\
\hline C18:1t11TVA & 0.77 & 2.15 & 1.46 & 0.19 & $<0.001$ \\
\hline C18:2n-6 & 2.89 & 2.00 & 2.45 & 0.10 & $<0.001$ \\
\hline$c 9 t 11 \mathrm{CLA}$ & 0.56 & 0.66 & 0.61 & 0.02 & 0.021 \\
\hline C18:3n-3 & 0.35 & 1.19 & 0.77 & 0.09 & $<0.001$ \\
\hline$C 20: 4 n-6$ & 0.24 & 0.14 & 0.19 & 0.01 & $<0.001$ \\
\hline SMCFA & 11.17 & 13.91 & 12.54 & 0.44 & $<0.001$ \\
\hline $\mathrm{C}: 12+\mathrm{C}: 14+\mathrm{C}: 16$ & 43.43 & 41.13 & 42.20 & 0.49 & 0.008 \\
\hline SFA & 75.65 & 78.30 & 76.98 & 0.60 & 0.024 \\
\hline MUFA & 20.25 & 17.71 & 18.98 & 0.55 & 0.016 \\
\hline PUFA & 4.09 & 3.99 & 4.04 & 0.07 & 0.477 \\
\hline$n-6$ & 3.18 & 2.15 & 2.66 & 0.12 & $<0.001$ \\
\hline$n-3$ & 0.36 & 1.19 & 0.77 & 0.09 & $<0.001$ \\
\hline$n-6 / n-3$ & 10.17 & 1.82 & 6.00 & 1.04 & $<0.001$ \\
\hline
\end{tabular}

Grazing significantly increased the contents of short chain fatty acids [butyric (C4:0), caproic (C6:0), caprylic (C8:0) and capric acids (C10:0)], stearic (C18:0), $\alpha$-linolenic (C18:3), total saturated fatty acids (SFA) and as well as significantly decreased the 
contents of the miristic (C14:0), miristoleic (C14:1), palmitoleic (C16:1), oleic acid (C18:1), linoleic (C18:2), arachidonic (C20:4) and total monounsaturated fatty acids (MUFA) in milk samples. On the contrary, the concentrations of lauric (C12:0), palmitic acid (C16:0) and total polyunsaturated fatty acids (PUFA) in milk samples did not show any significant differences between experimental periods.

Grazing significantly increased the concentrations of short and medium chain fatty acids (MCFA) in milk. These fatty acids are hydrolyzed rapidly and are absorbed directly to the liver via portal vein (Papamandjaris et al. 1998). Therefore the medium chain fatty acids have been used for patients that have malabsorption syndrome. Recently, the relations between the medium chain fatty acids and certain metabolic syndromes are summarized in a review report by Nagao and Yanagita (2010).

Concentrations of lauric, myristic and palmitic acids were lower in milk samples of the grazing group than in the control group. These acids are known to be hypercholesterolemic, whilst the other major saturated fatty acid (SFA), e.g. stearic acid, does not. Ulbricht and Southgate (1991) reported that these fatty acids to be responsible for increase the level of total and LDL cholesterol concentrations in blood serum.

The grazing positively affected the concentration of rumenic and vaccenic acids in the milk. The rumenic and vaccenic acids concentrations in the milk were 0.56 and 0.77 vs. 0.66 and $2.15 \%$ for hay based and experimental diet, respectively. The polyunsaturated fatty acids, such as linoleic and linolenic acid, are partly saturating in the rumen by biohydrogenation. Throughout this process the rumenic acid is formed from linoleic acid in the rumen by anaerobic bacteria (such as B. fibrisolvens), with vaccenic acid (t11C18:1)(TVA) as intermediates. TVA is converted to CLA by $\Delta^{9}$ desaturase in mammary gland (Bauman et al. 2001). Because of biohydrogenation in rumen, the relative percentage of $\mathrm{C} 18: 0$ was significantly increased in milk from grazing goats $(17.97 \%)$ compared to control group (10.71\%).

In present study, grazing significantly decreased the $n-6$ fatty acids and increased the n-3 fatty acids contents, however the n-6/n-3 ratios were favourable, 1.82 instead of 10.17. The $n-6 / n-3$ ratio is generally used to assess the nutritional value of fats. According to Simopoulos (2004), recommend value for the $n-6 / n-3$ ratio is less $4: 1$. The low ratio of $n-6 / n-3$ in the milk of grazing goats is meeting with the new recommendations for human nutrition. It is well known, that grass is rich in $\alpha$-linolenic acid, authors reported that $50-60 \%$ of the total fat is $n-3$ fatty acids in grass (Cabiddu et al. 2005; Tsvetkova and Angelow, 2010). The relatively unfavourable n-6/n-3 ratio in control group was probably due to lower n-3 fatty acids concentrations in hay which is affected by oxidative and leaf losses during hay making (Doreau and Poncet, 2000; Dewhurst et al., 2006). However, the relatively high PUFA content of grass is inhibiting de novo fatty acid synthesis in mammary gland (Couvrer et al., 2006). This confirmed by decrease of miristic and miristoleic fatty acids content of grazed goats' milk samples.

\section{Conclusions}

In conclusion, significant difference was found in milk composition, vitamin as well as fatty acid profile between two treatments. Grazing significantly increased the concentrations of vitamin $\mathrm{A}$ and $\mathrm{D}_{3}$, rumenic acid, short and medium chain fatty acids, as well as n-3 fatty acids in milk. These results show that grazing can enhance the nutrition value and quality of goat milk, consequently, consumers have nutraceutical 
benefits from consumption of milk from grazing goats due to higher concentrations of health promoting compounds.

Acknowledgements. The authors would like to thank for technical assistance of András Nagy, Komlóska. This work was supported by TAMOP projects (TÁMOP-4.2.1.B-11/2/KMR-2011-0003, TÁMOP-4.2.2.A-11/1/KONV-2012-0007) and Research Centre of Excellence- 8526-5/2014/TUDPOL project.

\section{REFERENCES}

[1] AOAC (1990): Association of Official Analytical Chemists: Official Methods of Analysis. 15th edition, Arlington, Virginia, USA. 963-965.

[2] Bergamo, P., Fedele, E., Iannibelli, L., Marzillo, G. (2003): Fat-soluble vitamins and fatty acid composition in organic and conventional Italian dairy products. - Food Chem. 82: 625-631.

[3] Cabiddu A., Decandia M., Addis M., Piredda G., Pirisi A., Molle G. (2005): Managing Mediterranian pastures in order to enhance the level of beneficial fatty acids in sheep milk. - Small Rumin. Res. 59: 169-180.

[4] Couvrer S., Hurtaud C., Lopez C., Delaby L., Peyraud J. L. (2006): The linear relationship between proportion of fresh grass in the cow diet, milk fatty acid composition and butter properties. - J. Dairy Sci. 89: 1956-1969.

[5] Frelich, J., Slachta, M., Hanus, O., Spicka, J., Samkova, E., Weglarz, A., Zapletal, P. (2012): Seasonal variation in fatty acid composition of cow milk in relation to the feeding system. - Animal Science Papers and Reports 30(3): 219-229.

[6] Dewhurst R. J., Shingfield K. J., Lee M. R. F., Scollan N. D. (2006): Increasing the concentrations of beneficial polyunsaturated fatty acids in milk produced by dairy cows in high-forage systems. - Anim. Feed Sci. Techn. 131: 168-206.

[7] Doreau M., Poncet C. (2000): Ruminal biohydrogenation of fatty acids originating from fresh or preserved grass. - Reprod. Nutr. Develop. 40: 201-209.

[8] Ip C., Chin S. F., Scimeca J.A., Pariza M.W. 1991. Mammary cancer prevention by conjugated dienoic derivative of linoleic acid. - Cancer Res. 51: 6118-6124.

[9] Kerti, A., Bardos L. (2006): Simultaneous determination of retinoids (retinol, retinyl palmitate), carotenoids (lutein, zeaxantin, b-cryptoxantin, lycopene, b-carotine) and vitamin E by rp-HPLC. - Clin. Exper. Lab. Med. 32: 106.

[10] Kondyli, E., Katsiari, M.C., Voutsina, L.P. (2007): Variations of vitamin and mineral contents in raw goat milk of the indigenous Greek breed during lactation. - Food Chemistry 100: 226-230.

[11] Kondyli, E., Svarnas, C., Samelis, J., Katsiari, M.C. (2012): Chemical composition and microbiological quality of ewe and goat milk of native Greek breeds. - Small Ruminant Research, 103: 194-199.

[12] Kuchtik J., Sustova K., Urban T., Zapletal D. (2008): Effect of the stage of lactation on milk composition, its properties and the quality of rennet curdling in East Friesian ewes. Czech J. Anim Sci. 53(2): 55-63.

[13] Nagao, K., Yanagita, T. (2010): Medium-chain fatty acids: Functional lipids for the prevention and treatment of the metabolic syndrome. - Pharmacological Research, 61: 208-212.

[14] Nicolosi R.J., Rogers E.J., Kritchevski D., Scimeca J.A., Huth P.J. (1997): Dietary conjugated linoleic acid reduces plasma lipoproteins and early aortic atherogenesis in hypercholesterolemic hamsters. - Artery 22: 266-277. 
[15] Novotna L., Kuchtik J., Sustova K,. Zapletal D,. Filipcik R. (2009): Effects of lactation stage and parity on milk yield, composition and properties of organic sheep milk. - J Appl. Anim Res. 36(1): 71-76.

[16] NRC (2007): Nutrient requirements of small ruminants: sheep, goats, cervids and camelids. - National Academy Press, Washington DC, USA

[17] Pajor, F., Steiber, O., Tasi, J. (2012): Influence of extensive grazing on cheese composition, yield and fatty acids content of goats. - Bulgarian Journal of Agricultural Science 18:(4) 487-492.

[18] Papamandjaris, A.A., MacDougall, D.E., Jones, P.J.H. (1998): Medium chain fatty acid metabolism and energy expenditure: obesity treatment implications. - Life Sci. 62: 12031215.

[19] Raynal-Ljutovac, K., Lagriffoul, G., Paccard, P., Guillet, I., Chilliard, Y. (2008): Composition of goat and sheep milk products: An update. - Small Ruminant Research 79: 57-72.

[20] Simopoulos A.P. (2004): Omega-6/Omega-3 essential fatty acid ratio and chronic diseases. - Food Rev. Inter. 20: 77-90.

[21] Soryal K.A., Zeng S.S., Min B.R., Hart S.P., Beyene F.A. (2004): Effect of feeding systems on composition of goat milk and yield of Domiati cheese. - Small Rumin. Res. 54: 121-129.

[22] Tsiplakou E., Mountzouris K.C., Zervas G. (2006): Concentration of conjugated linoleic acid in grazing sheep and goat milk fat. - Livest. Sci. 103: 74-84.

[23] Ulbright, T.L.V., Southgate, D.A.T. (1991): Coronary heart disease: seven dietary factors. - Lancet 338: 985-992. 